\title{
Being Good, Moral and Rational in a Context of Climate Change
}

\author{
Piotr Rosół \\ (The Maria Grzegorzewska University in Warsaw, prosol@aps.edu.pl)
}

Philosophy is the childhood of the intellect, and a culture that tries to skip it will never grow up.

Thomas Nagel (1989, p. 12)

\section{Introduction}

One of the main issues in ecophilosophy in our contemporary situation seems to be the translation of knowledge about possible dangers into political and social realities. Messages concerning the perils and risks of climate change and other environmental threats seem to be already wide spread. Whoever wants to listen and be informed can find a lot of information about the troublesome predicament of our planet. At the same time we seem to be lacking the motivation and determination to apply known solutions and strategies. In this paper, I would like to argue that we actually need more discussions and greater focus on the exchange of opinions, rather than focusing on action. I claim we need to search for the philosophical justifications of our approaches, even if this could be seen as distraction from our main problems. Why would we try to save roses while the forest is on fire? If I am right, it is the very lack of roses that has left us with a burning forest. This will be shown through the example of Thomas Nagel's typology of good, moral and rational life, but before I describe his classification, I would like to point to our awareness of climate change.

\section{Climate Change Consciousness}

We have recently heard Leonardo DiCaprio advocate collective action against climate change during his Oscar ceremony speech:

Making The Revenant was about man's relationship to the natural world. A world that we collectively felt in 2015 as the hottest year in recorded history. Our production needed to move to the southern tip of this planet just to be able to find snow. Climate change is real, it is happening right now. It is the most urgent threat facing our entire species, and we need to work collectively together and stop procrastinating. We need to support leaders 
around the world who do not speak for the big polluters, but who speak for all of humanity, for the indigenous people of the world, for the billions and billions of underprivileged people out there who would be most affected by this. For our children's children, and for those people out there whose voices have been drowned out by the politics of greed. I thank you all for this amazing award tonight. Let us not take this planet for granted (Griffits 2016).

The audience of this show, which exceeded 30 million people (see: Kissell 2016) not counting news coverage and retweeting and any other forms of reception, will have had a chance to hear Leonardo DiCaprio's contribution to the climate change debate. The moment of "Leonardo DiCaprio winning his first Oscar after six nominations" was one of the moments receiving highest attention from viewers (see: Baysinger 2016). So far, so good? Many people got to know about the problem of climate change. Perhaps they will be influenced by DiCaprio's words and change their attitude as well as put some pressure on politicians in order to change policies affecting the environment. This could help reduce the rate of global warming and potentially address other environmental issues.

The problem is that the context in which this message was given is also important for its impact. This context was not environmentally friendly. An Oscar ceremony is an occasion to sell advertisements and numerous firms are spending a lot of money to persuade viewers to their products. Cars were heavily advertised during the show. This reveals one of the reasons why we have a problem with climate change today. Put simply, the audience got an incoherent message. - "consume more" from ads and "consume less" or actually let's force big polluters to pollute less from DiCaprio speech. Although I do not want to underestimate the influence of such speeches, the problem is not the way they are formulated but rather the context in which we are perceiving them.

The message about the vulnerability of our planet, as well as the required behavioral changes, is also one of the main topics of Pope Francis' encyclical letter Laudatio Si. Just one quote showing how deeply the message of this text is connected with ecophilosophical thought:

If we approach nature and the environment without this openness to awe and wonder, if we no longer speak the language of fraternity and beauty in our relationship with the world, our attitude will be that of masters, consumers, ruthless exploiters, unable to set limits on their immediate needs. By contrast, if we feel intimately united with all that exists, then sobriety and care will well up spontaneously. The poverty and austerity of Saint Francis were no mere veneer of asceticism, but something much more radical: a refusal to turn reality into an object simply to be used and controlled (Pope Francis 2015). 
If this is not enough to convince us of the urgency of taking action and saving the planet, you can read books by scientists, who are also concerned about the current situation (Rees 2003) or political scientists and philosophers writing about the possible consequences of genetic engineering.

\section{Rational, Moral and Good Life}

In The View from Nowhere, Thomas Nagel describes the division between three aspects or forms of our obligations. One of the aspects would be the answer to the question of what would be rational to do; the second would be the answer to the question what we ought to do in a moral sense, what it would be good to do; the third provides us with the understanding of what we should do in order to preserve our lifestyle, way of life, the world-view we believe in, etc. (Nagel 1989, pp. 189-207). The last one quite often also translates into the answer to what we would do if we simply pay attention to our own particular interests as individuals. However, if we care about the interests of others it can already be moral, as well as rational, conduct and the establishment of a conception of a moral/rational life, which may and may not be in accordance with our concept of 'good life'.

Does it therefore seem that all three aspects of the good life and our obligations should be working in one direction - taking action in order to prevent climate change? The Pope describes to us what moral life would look like. Similarly (for those on the other side of the ethical spectrum) Peter Singer provides us with a textbook of our moral obligations criticizing our lack of empathy and unwillingness to help others (Singer 2010). DiCaprio confirms the conception of the good life and provides us with a role model, which could provide us with motivation for changing our lifestyles. Alternatively, Rees provides us with rational arguments for our responsible action, showing the looming dangers of scientific over-development, natural disasters and bad political choices. If we are all so well informed, why do we seem not to be acting accordingly?

\section{Motivation Issues}

At the same time many thinkers claim that the urgency of demands for action and the disastrous future which we may be forced to face (unless we take drastic steps to avoid it) is not having the impact we might expect. As Anthony Giddens puts it:

Attitude surveys show that most of the public accept that global warming is a major threat; yet only a few are willing to alter their lives in any significant way as a result. Among elites, climate change lends itself to gestural politics - grandiose-sounding plans largely empty of content (Giddens 2009, p. 2). 
Both Giddens (2009, p. 3) and Naomi Klein (2014, pp. 9-50) are searching for possible explanations for our, and our politicians, idleness in addressing the dangers posed by climate change. Also Peter Singer provides a series of common excuses justifying not helping others, which can be easily redeployed in the context of ignoring challenges of climate change (Singer 2010, pp. 23-62). Those range from bringing up the claims of those climate scientists who are denying human impact on temperature level and thus presenting the issue as disputable; to ignoring the issue by stating that the individual change does not have much of an impact or/and would be unfair, since others are not changing; as well as to postponing the effort, because we are habituated to the current state of affairs and our usual overestimation of pleasures available now in comparison with those of the future.

Having said this, the abovementioned authors disagree about the measures which need to be taken. According to Singer we need to concentrate on individual effort and determination of particular people, whose action will add up, helping the poor escape poverty and providing them with necessary resources in order to cope. Singer claims that we cannot rely on political actions due to powerful interest groups, which can make standard political mechanisms for reform obsolete. He names an example of a political battle over food subsidies and trade barriers, which was lost in Congress (even though Bush used his veto power to try to make it happen (Singer 2010, p. 114).

Singer's conception relies on rational arguments and a utilitarian ethical conception. In my interpretation, according to Singer the main issue remains the same as one of the crucial issues in the eyes of John Stuart Mill our pursuit of pleasure and avoidance of suffering should be understood in connection with other sentient beings. Therefore, the same factors which make us concerned with our pleasure and suffering should be universalized so as to include all people, as well as other beings able to feel pleasure and to suffer. $\mathrm{He}$ also thinks that our motivation to help others is unimportant compared to the effects of our actions (Singer 2010, pp. 66-67).

Thus if we go back to Nagel and his conception of the relationships between good, moral and rational life, he describes a position which seems to be very close to Singer's proposition:

Someone who finds himself convinced of the truth of a morality that makes impossible demands on him - such as utilitarianism if he is an affluent individual in a world of extreme inequality - may be able by a leap of self-transcendence to change his life so radically from the inside that service to this morality - to the welfare of mankind or of all sentient beings - becomes his overwhelming concern and his dominant good. This might be either a personal choice or something that he thinks everyone should do: a demand of human transformation (Nagel 1989, p. 206). 
Singer seems to foster both attitudes - asking us to commit ourselves to donating a bigger share of our income as a matter of personal choice, whilst at the same time searching for arguments which would allow the promotion of changes in culture and moral expectations, such that it would be a part of our moral obligation to give our share to charity (Singer 2010, pp. 154-169). This seems to be inadequate in the context of the challenges before us. The individual choice, lacking political support, not only may be not enough, but still needs some instances in order to coordinate our efforts. We should search for convergences (as Giddens would say) ensuing a more coherent attitude towards public policies. Therefore I think that avoiding the political side of our life and underestimating social stage seems to be a weakness of Singer's conception.

Giddens on the other hand tries to persuade us to accept gradual changes in policies and taxes, which will allow us to avoid bringing the problem of climate change into contemporary political conflicts. Giddens believes that staying away from rivalries between different sides of the political spectrum will help to keep the best practices of coping with climate change, even if the given political party will lose power. If the negotiations of climate policies include all factions, they will not depend on popular support, which can change quite abruptly. Another point he makes is stressing difficulties in keeping the public eager to act on their knowledge about climate change. If we would try to apply Nagel's conception to Giddens' attitude, it seems that for him the most important aspects are those connected with rational choices. People should have a frame for their action which will enable a compromise between economic development and concern for the climate. At the same time, according to Giddens, problems may arise from using too much ethical argumentation, as well as expecting too much in terms of lifestyle changes. Therefore, in Nagel's terms, that which is good to do and moral to do should be rather seen with caution and the most we can expect from bringing rational arguments. This also can be seen when he ends with technological optimism and sees one of the opportunities to cope with climate change in development of new devices and energy sources (Giddens 2009, pp. 114, 116, 149, 230).

We could say that Giddens makes interesting points in his struggle to achieve bipartisan support for policies, but I would defend a position already presented by Alexis de Tocqueville: "There is no country in the world in which everything can be provided for by the laws, or in which political institutions can prove a substitute for common sense and public morality" (2003, p. 101). In other words we really need to make climate change a part of our political and social life, otherwise we may end up only paying lip service to the whole problem, whereas the will and motivation won't be present. As I tried to show above, the rhetorical aspect of the presence of global problems seems to be already there, 
$[\mathrm{H}]$ owever, to move beyond rhetoric means deciding between those industries and activities that are sustainable and those that are not. Such a decision cannot be left to individual transactions and personal morality. In a world of uneven consumption patterns, sustainable development raises major questions of international distribution (Low 2003, p. 1).

In order to decide about such issues we need to have methods for conflict resolution and discussion platforms. Making climate change an issue outside of political camps will make it harder to question old ways and develop new ones, whereas with the passage of time, our knowledge will also change. Keeping it only a question of rational life (going again back to Nagel categories) will be harmful, among other factors, because we are not always inclined to do what is rational. Moral and 'good' life perspectives can be useful for expanding our motivational basis.

\section{VW As a Nietzschean Liar}

I believe that the changes which are needed include the way we discuss with each other, avoiding the instrumentalization of political, moral and social aspects of our actions, beliefs and commitments. We can easily show examples of corporations using public relations methods in order to assert their commitment to ecological goals and challenges while at the same time playing dirty with existing ecological norms and regulations. This festival of hypocrisy, which includes the BP spill in the Mexican Gulf and VW's scandal about emissions as very vivid examples, is undermining trust among different social actors and endangers not only our responses to climate change, but also the very basis of mutual understanding. Even if we do not share Kantian repulsion towards lying, we need still be concerned about such situations. Moreover, according to the Nietzschean view on lying from an extra-moral perspective, such cases are examples of unacceptable lying - the situation when we allow others make us believe in something which is not there.

The liar is a person who uses the valid designations, the words, in order to make something which is unreal appear to be real. He says, for example, "I am rich," when the proper designation for his condition would be "poor." He misuses fixed conventions by means of arbitrary substitutions or even reversals of names. If he does this in a selfish and moreover harmful manner, society will cease to trust him and will thereby exclude him. What men avoid by excluding the liar is not so much being defrauded as it is being harmed by means of fraud. Thus, even at this stage, what they hate is basically not deception itself, but rather the unpleasant, hated consequences of certain sorts of deception. It is in a similarly restricted sense that man now wants nothing but truth: he desires the pleasant, life-preserving consequences of truth (Nietzsche 1993, p. 81). 
How can we rely on negotiations with social actors, who are not telling the truth even from the point of view of Nietzsche? A similar problem can be seen in discussions about realizing values by European Union institutions. ${ }^{1}$ We can see that moral ideals are used in order to justify interests and lifestyle choices. In this context we need philosophy in order to remind ourselves about the difficult relationship between different categories of values and in order to resist compromising moral ideals in accordance with the instrumental attitude of many social actors.

\section{Why Should We Be Moral and Not Only Good Or Rational?}

Above mentioned situations, as well as problems with the justification of different moral categories and values, leads some philosophers to deny the important function of philosophy, to maintain that philosophers are losing themselves in rhetorical labyrinths. According to Richard Rorty, justifying our actions should be much simpler:

But one will take the question "Why should I be moral?" seriously only if one thinks that the answer "Because you might not be able to live with yourself if you thought yourself immoral" is not go od enough. But why should it not suffice? Only, it seems to me, because the person who doubts that she should be moral is already in the process of cobbling together a new identity for herself - one that does not commit her to doing the thing that her old identity took to be obligatory (Rorty 2007, p. 197).

Here, in Nagel's categories, we can see a domination of the 'good life' attitude. However, it is not so hard to imagine many contexts in which 'good life' will be in conflict with a moral and/or rational life. I can consume a lot and, in doing so, have an impression of following a proper ideal of 'good life' while at the same time putting a lot of pressure on the climate and the environment. If I am an individual this may be seen as unproblematic, as my impact is limited, and yet this is not the case, since different attitudes towards the relationship between what is good, what is moral and what is rational, concern almost everyone. My personal choice influences the general attitude and adds up with other individuals and their choices. In effect we can have a lot of people

\footnotetext{
1 "Larger countries delegated values-based policy to Brussels while they got on with the hard stuff, such as security or access to oil. For every pious expression of support for international justice or condemnation of capital punishment, there was a shabby energy deal or quiet support for a useful dictator. Some feel this category includes the Nord Stream 2 gas pipeline" (The Economist 2016a, p. 22). Not to mention situation in the US, where "in 2015 the Supreme Court reprimanded it [Environmental Protection Agency] for regulating mercury, arsenic and other substances emitted by power plants without taking proper account of the costs" and at the same time for 2017 Pentagon requested budget of 528.7 billion dollars (The Economist 2016b, p. 36-37).
} 
believing in having a 'good life' and not seeing that the planet is endangered as a result of their choices, not in spite of them. Again, philosophy seems to be a good place to search for balance between different attitudes in this respect.

In this context we should mention dangers from another side of the philosophical spectrum. Some people, when confronted with discussions and misunderstandings about philosophical issues, try to avoid them by saying that there should be one conception of reality, such as the scientific one, and that there we can find answers to our concerns. This sometimes leads towards attempts to diminish the role of ethics, by saying it should be naturalized (which will again leave us without moral life and only with 'good life' and rational life):

a purely naturalistic account of anything, including morality, leaves out of the field of its vision the world of subjective and interpersonal existence. The result is that scientific naturalism, at least as I have understood the term in this book, sees only a world without subjects as the real world. It is constrained then to interpret all subjective phenomena as ghostly intrusions or as having no reality at all. And if subjects seem to have little or no reality, then this can easily be taken to mean that they have little or no value either (Haught 2006, p. 156).

Similar concerns were expressed in connection with techno-science and its possible destructive influence on moral aspects of our lives:

science has played an important and often crucial role in exposing environmental damage and aiding opposition to it. But modern techno-science also has an uglier but less remarked face: technoscience has contributed to producing the environmental crisis at least as much as to curing it, applying to highly complex situations and systems specialized and highly instrumentallydirected forms of knowledge whose aim is to maximize outputs, often with devastating results (Plumwood 2005, p. 38).

As we can see the situation in which we consider only some aspects of our existence can lead to problematic situations. By letting ourselves concentrate on what is rational, or by unreflectively pursuing our lifestyle, we deprive ourselves of critical thinking tools, which can be helpful in the search for motivation and methods of changing our behaviours in order to avoid climate catastrophe.

All the viewpoints criticized in this paper seem to have one thing in common - they imply that the method of taking care of the best possible life is already invented and only needs interpretation of some rules and values in a new background of climate change. Whereas we may assume that newness of our situation is sufficiently great that we still need to work on our tools of 
understanding and that only after forging them we will be able to find new answers to climate change. Quoting Nagel:

Too much time is wasted because of the assumption that methods already in existence will solve problems for which they were not designed; too many hypotheses and systems of thought in philosophy and elsewhere are based on the bizarre view that we, at this point in history, are in possession of the basic forms of understanding needed to comprehend absolutely anything. I believe that the methods needed to understand ourselves do not yet exist (Nagel 1989, p. 10).

A reflection on the relationship between 'good', moral and rational life, conveys one of the points to be taken into consideration, while searching for a way to respond to contemporary environmental challenges.

\section{References}

Baysinger, T. 2016. "These Are the Oscar Ads and Moments Viewers Paid Attention to the Most." Adweek. URL: http://www.adweek.com/tvvideo/these-are-oscar-ads-and-moments-viewers-paid-attention-most169909/ (retrieved on 04.03.2016.)

The Economist. 2016a. "Charlemagne: Value Shoppers." The Economist Jan $28^{\text {th }}$. URL: http://www.economist.com/news/europe/21689602-europepromised-principled-foreign-policy-now-it-desperate-quick-deals-valueshoppers (retrieved on 04.03.2016.)

The Economist. 2016b. "Climate Change: Supreme Emissions." The Economist Feb 11 $1^{\text {th }}$ URL: http://www.economist.com/news/unitedstates/21692907-nine-justices-press-pause-one-presidents-proudestachievements-supreme (retrieved on: 04.03.2016.)

Giddens, A. 2009. The Politics of Climate Change. Cambridge: Cambridge University Press.

Griffits, K. 2016. “Transcript of Leonardo DiCaprio's Oscars Acceptance Speech Gets Political About Climate Change - VIDEO." Bundle. URL: https://www.bustle.com/articles/144803-transcript-of-leonardodicaprios-oscars-acceptance-speech-gets-political-about-climatechange-video (retrieved on 04.03.2016.)

Haught, J. F. 2006. Is Nature Enough? Meaning and Truth in the Age of Science. New York: Cambridge University Press.

Kissell, R. 2016. "Final Oscar Ratings: 34.4 Million Viewers, Down Only 2\% Among Blacks.” Variety. URL: http://variety.com/2016/tv/news/ oscars-ratings-snapshot-34-4-million-slight-decline-among-blacks1201719378/ (retrieved on 04.03.2016.)

Klein, N. 2014. This Changes Everything: Capitalism vs. The Climate. Toronto: Simon \& Schuster. 
Low, N. 2003. Global Ethics and Environment. New York: Routledge.

Nagel, T. 1989. The View from Nowhere. Oxford: Oxford University Press.

Nietzsche, F. 1993. Philosophy and Truth. Selections from Nietzsche's Notebooks of the early 1870's. New Jersey: Humanity Books.

Plumwood, V. 2005. Environmental Culture. The Ecological Crisis of Reason. London: Psychology Press.

Pope Francis. 2005. Laudato Si. URL: https://w2.vatican.va/content/dam/ francesco/pdf/encyclicals/documents/papa-francesco_20150524_enciclicalaudato-si_en.pdf (retrieved on 04.03.2016.)

Rees, M. 2003. Our Final Hour: A Scientist's Warning: How Terror, Error, and Environmental Disaster Threaten Humankind's Future In This Century On Earth and Beyond. New York: Basic Books.

Rorty, R. 2007. "Kant vs. Dewey." In R. Rorty (ed) Philosophy as Cultural Politics (pp. 183-202). New York: Cambridge University Press.

Singer, P. 2010. The Life You Can Save: How To Do Your Part To End World Poverty. New York: Random House Trade.

Tocqueville, de A. 2003. Democracy in America. New Jersey: The Lawbook Exchange. 
Piotr Rosół

(The Maria Grzegorzewska University in Warsaw, prosol@aps.edu.pl)

\title{
Being Good, Moral and Rational in a Context of Climate Change
}

\begin{abstract}
Climate change has become a popular topic with a strong presence in media, political, scientific and ethical debates. This raises a question as to why we are not acting in accordance with our knowledge and are unable to do enough to protect our future. The paper argues that the problem partly arises from a lack of philosophical reflection about relations between different aspects of our personalities. Those different aspects are presented based on the reflections of Thomas Nagel on good, moral, and rational ways of life. I claim that all three need to be taken into consideration in order to answer challenge raised by the environmental dangers we are facing.
\end{abstract}

Keywords: good life, moral life, rational life, climate change, Thomas Nagel, enviromental ethics

Ethics in Progress (ISSN 2084-9257). Vol. 7 (2016). No. 1, Art. \#3, pp. 21-31.

doi: 10.14746/eip.2016.1.2 